\title{
Postnatal catch-up fat after late preterm birth
}

\author{
Maria L. Giannì', Paola Roggero', Nadia Liotto', Orsola Amato', Pasqua Piemontese', Daniela Morniroli', Beatrice Bracco' \\ and Fabio Mosca'
}

BACKGROUND: Late preterm birth accounts for $70 \%$ of preterm births. The aim of the study was to investigate the postnatal weight gain and weight gain composition changes in a cohort of late preterm infants.

METHODS: A total of 49 late preterm infants (mean birth weight 2,496 $\pm 330 \mathrm{~g}$ and gestational age 35.2 $\pm 0.7 \mathrm{wks}$ ) underwent growth and body composition assessment by an air displacement plethysmography system on the fifth day of life, at term, and at 1 and 3 mo of corrected age. The reference group was composed of 40 healthy, full-term, breast-fed infants.

RESULTS: The late preterm infants showed a $\triangle$ fat mass gain between birth and term-corrected age equal to 182\%. As compared with full-term infants, at term and 1 mo of corrected age mean weight $(3,396 \pm 390$ vs. 3,074 $\pm 409 \mathrm{~g}$ and 4,521 $\pm 398 \mathrm{vs}$. $4,235 \pm 673 \mathrm{~g}$, respectively) and percentage of fat mass (16.1 \pm 4.6 vs. $8.9 \pm 2.9$ and $22.6 \pm 4.2$ vs. $17.4 \pm 4.0$, respectively) were significantly higher in late preterm infants, whereas no difference among groups was found at 3 mo.

CONCLUSION: Rapid postnatal catch-up fat was found in these infants. Further studies are needed to investigate whether this short-term increase in fat mass may modulate the risk of chronic diseases or represent an adaptive mechanism to extrauterine life.

$\mathbf{L}$ ate preterm birth is defined as a birth that occurs between $340 / 7$ and 36 6/7 wk of gestation. The proportion of late preterm births has markedly increased during the past two decades, accounting for $70 \%$ of preterm births (1). Late preterm infants have been recognized as a high-risk group of infants as they present unique physiology and greater risks in terms of mortality and morbidity as compared with full-term infants $(2,3)$.

There is evidence that monitoring not only the quantity but also the quality of growth, in terms of body composition changes, may play an important role in gaining further insight into the relationship between birth weight and time in utero on early growth pattern and future health (4-6). Indeed, extremely preterm infants, assessed at term-corrected age, have been found to be at increased risk for developing increased and/or aberrant adiposity, which is a known risk marker for cardiovascular disease $(7,8)$. However, it has been reported that preterm infants born appropriate for gestational age succeed in recovering growth and fat mass within the third month of corrected age (9). To our knowledge, data regarding the early dynamic features of growth and body composition changes of late preterm infants are scarce. Santos et al. recently reported that late preterm infants are at increased risk of failure to thrive during the first 2 years of life (10).

The aim of our study was to investigate the body composition of late preterm infants at birth and to evaluate the postnatal weight gain and changes in body composition in a cohort of late preterm infants during the first 3 mo of corrected age in comparison with full-term infants.

\section{RESULTS}

Growth and body composition were assessed in 49 late preterm infants. Basic subject characteristics of the late preterm and full-term infants at birth are shown in Table 1. As expected, gestational age, birth weight, length, and head circumference in the late preterm infants were significantly smaller than in the full-term infants, whereas no significant difference in the percentage of males between the two groups was found. Sixtyseven percent $(n=33)$ of the late preterm infants were born by vaginal delivery. All late preterm infants were breastfed for at least $50 \%$ of total milk intake. No difference in maternal characteristics between the late preterm and the full-term infants was found (Table 2). Anthropometric parameters of the late preterm and full-term infants at each study point are shown in Table 3. The late preterm infants showed higher mean weight values than the full-term infants at term and 1 mo of corrected age, whereas at 3 mo no significant difference between the two groups was found. No difference in terms of length and head circumference values were found between the late preterm and full-term infants through the study.

Mean percentage (SD) of fat mass in the late preterm infants on the fifth day of life was significantly lower than that of the full-term infants at birth (5.7 (3.9) vs. 8.9 (2.9), respectively, $P<0.0001)$. Mean percentage of fat mass was significantly higher in the late preterm infants as compared with the fullterm infants at term and 1 mo of corrected age (Table 4). The late preterm infants showed a mean (SD) $\Delta$ fat mass gain between the fifth day of life and term corrected age equal to $182 \%$ (43). Mean $\Delta$ fat mass gain from term up to the third month of corrected age was significantly lower than that of the full-term infants (Figure 1). However, at 3 mo of corrected age, 


\section{Articles | Giannietal.}

Table 1. Characteristics of the late preterm and full-term infants at birth

\begin{tabular}{|c|c|c|c|c|c|}
\hline & Males, $n(\%)$ & $\mathrm{GA}(w \mathrm{k})$ & Weight (g) & Length $(\mathrm{cm})$ & $\begin{array}{l}\text { Head circumference } \\
(\mathrm{cm})\end{array}$ \\
\hline Late preterm infants & $21(43)$ & $35.2(0.7)^{*}$ & $2,496(330)^{*}$ & $44.8(1.7)^{*}$ & $31.6(1.2)^{*}$ \\
\hline
\end{tabular}

Data are expressed as mean (SD) or $n$ (\%).

$\mathrm{GA}$, gestational age.

${ }^{*} P<0.0001$.

Table 2. Maternal characteristics

\begin{tabular}{lcc}
\hline & $\begin{array}{c}\text { Late } \\
\text { preterm }\end{array}$ & Term \\
\hline Age $(\mathrm{y})$ & $34.2(5.2)$ & $33.1(4.7)$ \\
$\mathrm{BMI}\left(\mathrm{kg} / \mathrm{m}^{2}\right)$ & $22.7(4.2)$ & $22.6(4.5)$ \\
Weight gain during pregnancy $(\mathrm{kg})$ & $11.3(3.7)$ & $12.1(4.6)$ \\
Gestational hypertension/preeclampsia, $n(\%)$ & $4(8)$ & None \\
Smokers, $n(\%)$ & $6(12)$ & None \\
\hline
\end{tabular}

Data are expressed as mean (SD) or $n(\%)$.

mean percentage of fat mass in the late preterm infants reached values comparable with those of full-term infants.

\section{DISCUSSION}

This explorative study presents data related to the body composition changes in a cohort of late preterm infants during the first 3 mo of corrected age. As expected, late preterm infants at birth showed a significantly lower birth weight and percentage of fat mass as compared with full-term infants. Indeed, it is well known that the last trimester of pregnancy is characterized by a major accretion in body weight and fat mass (11). However, at term and 1 mo of corrected age, the late preterm infants were heavier than the full-term infants and achieved a mean body weight value comparable with their counterparts by the third month of corrected age. In addition, between birth and term-corrected age, the late preterm infants showed a great increase in fat mass so that they were fatter than their counterparts at birth. From term up to the third month of corrected age, the late preterm infants showed lower fat mass gains than the full-term infants and, as a result, the percentage of fat mass was comparable between the two groups at 3 mo of age.

To our knowledge, there is a paucity of data concerning the postnatal growth and body composition changes in late preterm infants. Santos et al. (10) aimed to evaluate the consequences of being born late preterm on later growth. These authors reported that $3.4 \%$ and $3 \%$ of a cohort of 371 late preterm infants were at increased risk of being underweight at 1 and 2 years of age, respectively. These findings could be partly explained by the negative effect on growth associated with the higher hospitalization rates reported for late preterm infants in the first years of life $(12,13)$. In addition, as the prevalence of late preterm birth in the population studied was higher in the low-income families, the late preterm infants enrolled in that study could present environmental and economic constraints on growth.

With regard to body composition, this study reports longitudinal data on the dynamic changes in body composition of late preterm infants during the first months of corrected age in comparison with full-term infants. On the basis of our results, the rapid weight growth shown by the late preterm infants is accompanied by a major increase in the percentage of fat mass that takes place mostly during the first weeks of life. These findings are consistent with previous results reported by other authors with regard to extremely preterm infants. It has been found that extremely preterm infants, including those born small for gestational age, show a major deposition of fat mass in early postnatal life so that they show an increased adiposity at term-corrected age $(7,14)$. However, within the first 3-4 mo of corrected age, extremely preterm infants succeed in achieving fat mass values similar to those of full-term infants $(9,15)$.

The rapid fat deposition experienced by the late preterm infants could represent an adaptive mechanism to postnatal life. It is well acknowledged the fetus and preterm infant are different with regard to the environment and the nutritional supply. Indeed, late preterm infants, as they switch from intrauterine to extrauterine life, have to maintain thermoregulation, fluid balance, and breathing even in the absence of major clinical problems. Moreover, amino acid delivery immediately after birth does not match the high fetal protein intake (16). In addition, it has been suggested that catch-up growth may lead to a state of skeletal muscle insulin resistance, which seems to be strictly associated with an accelerated rate of deposition of fat mass rather than fatfree mass (FFM) (17). The adipose tissue appears to exert a specific control of thermogenesis, i.e., thermogenesis is suppressed by the depleted adipose fat stores during starvation, to spare energy. When refeeding takes place, deposition of fat mass is greater than that of FFM due to the fact that thermogenesis remains suppressed to promote catch-up fat. Instead of being used in the skeletal muscle glucose is redistributed for lipogenesis and storage in the adipose tissue. This preferential "catch-up fat" can eventually lead to an increased adiposity that, in association with adipose tissue hyper-responsiveness and hyperinsulinemia, may represent an additional risk factor for the development of the metabolic syndrome in young adulthood (17). On the basis of these experimental studies, the rapid catch-up fat shown by the late preterm infants could be partially explained by the fact that the infants enrolled in this study were relatively "underfed" in the first days of life.

This explorative, longitudinal study provides preliminary evidence regarding growth and weight gain composition of late preterm infants vs. full-term infants during the first 
Table 3. Anthropometric parameters of the late preterm and full-term infants at each study point

\begin{tabular}{|c|c|c|c|c|c|c|}
\hline & \multicolumn{2}{|c|}{ Weight (g) } & \multicolumn{2}{|c|}{ Length $(\mathrm{cm})$} & \multicolumn{2}{|c|}{ Head circumference $(\mathrm{cm})$} \\
\hline & Late preterm & Full term & Late preterm & Full term & Late preterm & Full term \\
\hline Term/birth & $3,396(390)^{* *}$ & $3,074(409)$ & $49.5(1.9)$ & $49.3(2.0)$ & $34.8(1.0)$ & $34.2(1.1)$ \\
\hline $3 \mathrm{mo}$ & $6,050(485)$ & $5,978(580)$ & $59.6(2.1)$ & $60.6(2.5)$ & $40.4(1.2)$ & $39.9(1.3)$ \\
\hline
\end{tabular}

Data are expressed as mean (SD).

${ }^{*} P=0.002 ; *{ }^{*} P<0.0001$.

Table 4. Mean fat mass values (\%) in the late preterm and full-term infants

\begin{tabular}{lcr}
\hline & Late preterm & Full term \\
\hline Term & $16.1(4.6)^{* *}$ & $8.9(2.9)$ \\
$1 \mathrm{mo}$ & $22.6(4.2)^{*}$ & $17.4(4.0)$ \\
$3 \mathrm{mo}$ & $26.7(4.3)$ & $27.1(3.9)$ \\
\hline
\end{tabular}

Data are expressed as mean (SD).

${ }^{*} P=0.002 ;{ }^{* *} P<0.0001$.

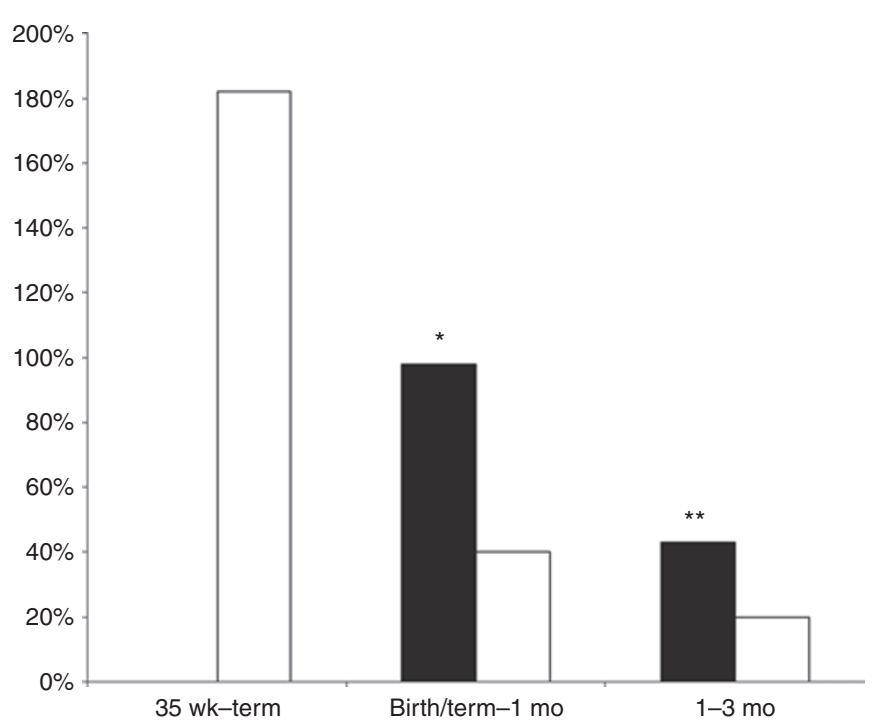

Figure 1. Mean $\Delta$ fat mass gains in the late preterm and full-term infants. Black bars, full-term infants; white bars, late preterm infants. ${ }^{*} P=0.007$ full-term vs. preterm infants; ${ }^{* *} P=0.004$ full-term vs. late preterm infants.

months of corrected age. Larger studies are needed to confirm these data and further elucidate the clinical implications of the early postnatal catch-up fat shown by the late preterm infants.

\section{METHODS}

Informed consent was obtained from the infants' parents and the study design was approved by the Departmental Ethics Committee, Fondazione IRCCS Cà Granda Ospedale Maggiore Policlinico, Milano, Italy.

\section{Patients}

A total of 49 late preterm infants were included in the study. Forty fullterm, healthy, breast-fed infants constituted the reference group (18).

Inclusion criteria were the following: gestational age from $340 / 7$ to 36 6/7 wk; singleton pregnancy; being born appropriate for gestational age according to Fenton's growth chart (19); and Caucasian parentage. Exclusion criteria were the presence of congenital diseases; chromosomal abnormalities; severe cardiac, brain, renal, endocrinologic, or gastrointestinal diseases; sepsis documented by positive blood culture; need of intravenous fluids or parenteral nutrition; prepregnancy maternal BMI > 30; and prepregnancy diseases.

\section{Study Design}

We conducted an explorative, observational, longitudinal study. Infants were enrolled at birth. At enrollment, basic subject characteristics (birth weight, length, head circumference, gestational age, and gender) were recorded prospectively. Gestational age was based on the last menstrual period and first trimester ultrasonogram. Corrected age was calculated using the chronologic age and adjusting for gestational age, that is, for the number of additional weeks from term $(40 \mathrm{wk})$. The following maternal variables were also recorded: age; prepregnancy BMI; smoking; weight gain during pregnancy; gestational hypertension and/or preeclampsia, defined, respectively, as de novo hypertension (systolic blood pressure $\geq 140 \mathrm{~mm} \mathrm{Hg}$ or diastolic blood pressure $\geq 90 \mathrm{~mm} \mathrm{Hg}$ ) arising after mid-pregnancy and gestational hypertension associated with new-onset proteinuria ( $\geq 300 \mathrm{mg} / 24 \mathrm{~h})$; and mode of delivery.

\section{Nutritional Practices}

With regard to late preterm infants, breastfeeding practice was encouraged in all mother-infant pairs. In case of insufficient breastfeeding, a term formula was used. Full-term infants were exclusively breastfed.

\section{Growth and Body Composition Assessment}

With regard to the late preterm infants, anthropometric measurements and body composition were assessed on the fifth day of life, at term, and at 1 and 3 mo of corrected age. The full-term infants were measured at birth (third day of life), and at 1 and 3 mo of age. Body weight, length, and head circumference were measured according to standard procedures (20). The weight of each baby was measured on an electronic scale accurate to $\pm 0.1 \mathrm{~g}$ (PEA POD Infant Body Composition System; Cosmed, Concord, CA). Body length was measured to the nearest $1 \mathrm{~mm}$ on a Harpenden neonatometer (Holtain, Crymych, UK). Head circumference was measured to the nearest $1 \mathrm{~mm}$ using nonstretch measuring tape. All measurements were performed by trained nurses.

Body composition was assessed using an air displacement plethysmography system (PEA POD Infant Body Composition System). A detailed description of the PEA POD's physical design, operating principles, validation, and measurement procedures is provided elsewhere $(21,22)$. Briefly, the PEA POD assesses fat mass and "FFM" by direct measurements of body mass and volume and the application of a classic densitometric model in which percentage of body fat is calculated using body density and predetermined fat and FFM density values. Body fat was defined as body weight minus FFM. A constant fat mass density value of $0.9007 \mathrm{~g} / \mathrm{ml}$ was used. FFM density values are calculated as the sum of the contributions of the various components in the FFM compartment. Age and sex-specific FFM density values extrapolated from data reported in previous multicompartment model studies were used.

The changes in fat mass $[100 \times($ fat mass at second examination - fat mass at first examination)/fat mass at first examination)] were also calculated. With regard to the late preterm infants, the changes in fat mass were calculated between birth and termcorrected age, term-1 mo, and 1-3 mo of corrected age, whereas in the full-term infants, the changes were calculated between birth and $1 \mathrm{mo}$, and $1-3 \mathrm{mo}$. 


\section{Statistical Analysis}

A $\chi^{2}$ test was used for comparisons between discrete variables. Differences between and among infants in repeated measurements of growth parameters and fat mass were assessed by ANOVA. Statistical significance was set at a level of 0.05 . All statistical analyses were performed using SPSS (SPSS, version 12; SPSS, Chicago, IL).

\section{STATEMENT OF FINANCIAL SUPPORT}

No financial assistance was received to support this study.

\section{REFERENCES}

1. Dong Y, Yu JL. An overview of morbidity, mortality and long-term outcome of late preterm birth. World J Pediatr 2011;7:199-204.

2. Teune MJ, Bakhuizen S, Gyamfi Bannerman C, et al. A systematic review of severe morbidity in infants born late preterm. Am J Obstet Gynecol 2011;205:374.e1-9.

3. Lanari M, Silvestri M, Rossi GA. Respiratory syncytial virus risk factors in late preterm infants. J Matern Fetal Neonatal Med 2009;22:Suppl 3:102-7.

4. Singhal A, Lucas A. Early origins of cardiovascular disease: is there a unifying hypothesis? Lancet 2004;363:1642-5.

5. Dulloo AG, Jacquet J, Seydoux J, Montani JP. The thrifty "catch-up fat" phenotype: its impact on insulin sensitivity during growth trajectories to obesity and metabolic syndrome. Int J Obes (Lond) 2006;30:Suppl 4:S23-35.

6. Morrison JL, Duffield JA, Muhlhausler BS, Gentili S, McMillen IC. Fetal growth restriction, catch-up growth and the early origins of insulin resistance and visceral obesity. Pediatr Nephrol 2010;25:669-77.

7. Roggero $\mathrm{P}$, Giannì ML, Amato O, et al. Is term newborn body composition being achieved postnatally in preterm infants? Early Hum Dev 2009;85:349-52.

8. Cooke RJ, Griffin I. Altered body composition in preterm infants at hospital discharge. Acta Paediatr 2009;98:1269-73.

9. Roggero P, Giannì ML, Liotto N, et al. Rapid recovery of fat mass in small for gestational age preterm infants after term. PLoS ONE 2011;6:e14489.

10. Santos IS, Matijasevich A, Domingues MR, Barros AJ, Victora CG, Barros FC. Late preterm birth is a risk factor for growth faltering in early childhood: a cohort study. BMC Pediatr 2009;9:71.
11. Micheli JL, Pfister R, Junod S, et al. Water, energy and early postnatal growth in preterm infants. Acta Paediatr Suppl 1994;405:35-42.

12. McLaurin KK, Hall CB, Jackson EA, Owens OV, Mahadevia PJ. Persistence of morbidity and cost differences between late-preterm and term infants during the first year of life. Pediatrics 2009;123:653-9.

13. Escobar GJ, Clark RH, Greene JD. Short-term outcomes of infants born at 35 and 36 weeks gestation: we need to ask more questions. Semin Perinatol 2006;30:28-33.

14. Giannì ML, Roggero P, Taroni F, Liotto N, Piemontese P, Mosca F. Adiposity in small for gestational age preterm infants assessed at term equivalent age. Arch Dis Child Fetal Neonatal Ed 2009;94:F368-72.

15. Ramel SE, Gray HL, Ode KL, Younge N, Georgieff MK, Demerath EW. Body composition changes in preterm infants following hospital discharge: comparison with term infants. J Pediatr Gastroenterol Nutr 2011;53:333-8.

16. Sauer PJ. Can extrauterine growth approximate intrauterine growth? Should it? Am J Clin Nutr 2007;85:608S-13S

17. Dulloo AG, Jacquet J, Seydoux J, Montani JP. The thrifty "catch-up fat" phenotype: its impact on insulin sensitivity during growth trajectories to obesity and metabolic syndrome. Int J Obes 2006;4:S23-35.

18. Roggero $\mathrm{P}$, Giannì ML, Orsi $\mathrm{A}$, et al. Quality of growth in exclusively breast-fed infants in the first six months of life: an Italian study. Pediatr Res 2010;68:542-4.

19. Fenton TR. A new growth chart for preterm babies: Babson and Benda's chart updated with recent data and a new format. BMC Pediatr 2003;3:13.

20. Agostoni C, Grandi F, Giannì ML, et al. Growth patterns of breast fed and formula fed infants in the first 12 months of life: an Italian study. Arch Dis Child 1999;81:395-9.

21. Ma G, Yao M, Liu Y, et al. Validation of a new pediatric air-displacement plethysmograph for assessing body composition in infants. Am J Clin Nutr 2004;79:653-60.

22. Ellis KJ, Yao M, Shypailo RJ, Urlando A, Wong WW, Heird WC. Bodycomposition assessment in infancy: air-displacement plethysmography compared with a reference 4-compartment model. Am J Clin Nutr 2007;85: $90-5$. 